\title{
A Two-Stage Model for Project Optimization in Transportation Infrastructure Management System
}

\author{
Zhang Chen, ${ }^{1}$ Liyuan Liu, ${ }^{1} \mathrm{Li}$ Li, ${ }^{1}$ and Hui $\mathrm{Li}^{2}$ \\ ${ }^{1}$ Key Laboratory of Road and Traffic Engineering of the Ministry of Education, Tongji University, Shanghai 201804, China \\ ${ }^{2}$ Department of Civil and Environmental Engineering, University of California, Davis, CA 95616, USA \\ Correspondence should be addressed to Li Li; 622lilian@tongji.edu.cn
}

Received 11 April 2014; Revised 3 June 2014; Accepted 18 June 2014; Published 13 July 2014

Academic Editor: X. Zhang

Copyright (c) 2014 Zhang Chen et al. This is an open access article distributed under the Creative Commons Attribution License, which permits unrestricted use, distribution, and reproduction in any medium, provided the original work is properly cited.

\begin{abstract}
Mathematical optimization is very important for project decision in the Transportation Infrastructure Management System (TIMS). However, it has not been widely employed in TIMS due to poor performance of conventional optimization models in calculation speed and practical application. Therefore, it is necessary to improve the performance of optimization models. According to the process of decision-making in transportation management, a novel two-stage project optimization model, including budget allocation and project distribution, was proposed in this paper. Moreover, the methods of dynamic programming (DP) and genetic algorithm (GA) were applied to obtain an effective solution. The findings indicate that the new optimization method can provide a satisfactory and reasonable maintenance schedule for transportation infrastructure maintenance agencies whose routine management will benefit from the newly proposed model.
\end{abstract}

\section{Introduction}

Transportation infrastructure includes roads, bridges, tunnels, airports, railways, and seaports. As a result, Transportation Infrastructure Management System (TIMS) correspondingly covers many subsystems, among which Pavement Management System (PMS) and Bridge Management System (BMS) are the most important ones. Whatever kind of subsystem it is, project optimization is a key element in the process of decision-making for the infrastructure management. Specifically, project optimization [1] refers to finding an optimal maintenance strategy with maximized benefit through arranging pavement maintenance reasonably in terms of time and space in the planning period. Most of existing research efforts on project optimization of TIMS focused on PMS.

Since decision supporting system was introduced into the second generation of PMS, project optimization has been paid much attention by pavement researchers and management agencies. Currently, there are mainly two categories of project optimization methods for network-level pavement management system, namely, prioritization method and mathematical optimization $[2,3]$. Prioritization method is to carry out project selection based on some principles prescreened and then to determine the maintenance strategy for each year in the planning period. In 1994, Hass et al. [4] summarized the characteristics of different prioritization methods, among which the two most popular methods are based on infrastructure performance parameters and economic analysis parameters. The prioritization method based on performance parameters is adopted to arrange road maintenance projects by California, US, where road roughness, damaged condition, and average daily traffic volume are considered as influencing factors to develop the prioritization principles. Hudson uses rainfall, number of freeze-thaw cycles, and damage severity as parameters to establish an expression for prioritization through regression or variance analysis so as to determine the priority index of every section requiring reconstruction in the road network. While prioritization based on performance parameters is convenient for calculation and of high pertinence, the results may be far from the economic optimum. Thus the prioritization method based on economic analysis parameters is relatively advanced regarding economic optimum. In 
1980s, the prioritization method based on economic analysis parameters was very popular [5-8]. The State of Washington, US, used the total cost, including initial project construction cost, maintenance cost, user operating expense, delay cost, and pavement salvage, as the prioritization indicator in their PMS while the performance index was adopted in UK. At the same time, Hass et al. used equivalent annual cost in Canada, which refers to the ratio of the project construction cost and the corresponding expected lifetime to sequence. Among the PMSs adopting the prioritization method, the most typical one is PAVER in US. PAVER uses the method of benefitcost-increment to determine the priorities of maintenance projects according to budget optimization. Another representative one is the Pavement Maintenance Decision Support System of Shanghai (PMDSSS), China. According to different managerial preferences of road administrators and agencies, this PMDSSS has developed eight different prioritization principles taking into account either performance parameters or economic analysis parameters or both, with different combinations of traffic volume, pavement damage condition, riding quality, structural capability, and economic indicators. The principles greatly help policy makers to formulate large or medium maintenance plans and long-term rehabilitation strategies in the planning years. However, the tradeoff between the maintenance strategy and the time has not been included in the prioritization method, which leads to huge disparity between the calculated result and the actual optimal solution. Therefore, many researchers have been, instead, focusing on the mathematical optimization, which refers to considering each project in the planning period, the possible maintenance plan, and the implementation schedule through mathematical calculations.

The idea of optimization using mathematical method was proposed in 1970. The mathematical optimization for PMS falls into two categories: static and dynamic. Integer programming is mostly used in the former. For instance, PMS in Denmark [9], HDM-III in World Bank [10], RAMS of Texas, US, and PARS of Ontario, Canada, all adopt 0-1 integer programming $[11,12]$. PMS in the State of Indiana, US $[13,14]$, uses the number of workday needed for maintenance as the decision variable, and constraints from budget, manpower, machine, and material are also included to build up the integral programming model. In the dynamic programming, PMS of Arizona, US [15], was the first to successfully introduce Markov decision process to the network-level pavement management system. When improving the PAVER system, Feighan et al. [16] managed to develop the strategy for maintenance and reconstruction that minimizes the cost of road network through dynamic programming. In 1994, Liu and Yao [17] used Markov decision process to minimize maintenance cost. In 1995, Zou [18] formulated a dynamic model to predict the pavement performance and the adaptive iteration algorithm. In addition, to solve the problems of pavement maintenance strategy, he adopted the analytical hierarchy process model and the heuristic optimization technique. In 2001, Nunoo [19] optimized the maintenance plan of integrated pavement using shuffled complex evolution algorithm. In 2003, Chan et al. [20, 21] attempted to use genetic algorithm to develop a multiobjective programming model to optimize the strategy for highway pavement maintenance. Meanwhile, they adopted heuristic algorithm to yield the result. Ferreira et al. [22] also developed a probabilistic segment-linked optimization model together with a genetic algorithm heuristic with the objective of minimizing total discounted cost of M\&R actions. While mathematical optimization can produce the optimal calculation results, the large number of factors to be considered, huge data processing, and barely satisfactory calculation speed greatly limit its practical application. In order to apply mathematic optimization to project optimization, the key point is to find a model or algorithm which can save computing resources as well as meeting the practical needs.

Compared to the existing research studies, the main contributions of this paper are listed as follows. Firstly, the project optimization is separated into two independent and interrelated processes, namely, budgets allocation and project distribution, and a new two-stage model is developed. Secondly, the technique of dynamic programming (DP) and genetic algorithm (GA) are applied to solve the model and yield an effective solution. Finally, the new programming method is verified to be effective through the case study in Shanghai and the poor calculation speed and the practical application limitations of conventional methods are improved.

\section{Integer Programming in Conventional Project Optimization}

Integer programming (IP) in the conventional project optimization model can be stated as follows:

$$
\begin{gathered}
\text { Objective } \max Z=\sum_{t=1}^{T} \sum_{i=1}^{N} \sum_{j=1}^{m} X_{i j t} * B_{i j t} \\
\text { Subject to } \sum_{t=1}^{T} \sum_{i=1}^{N} \sum_{j=1}^{m} X_{i j t} * C_{i j t} \leq A \\
\sum_{j=1}^{m} X_{i j t}=1 \quad(i=1,2, \ldots, N ; t=1,2, \ldots, T)
\end{gathered}
$$

$X_{i j t}= \begin{cases}1 & \text { if treatment } j \text { is applied in segment } i \text { in year } t \\ 0 & \text { otherwise }\end{cases}$

$$
B_{i j t}, C_{i j t}, A, S_{t}, V_{t}>0
$$

where $Z$ is total maintenance benefit; $B_{i j t}, C_{i j t}$ are, respectively, the benefit and cost caused by implementing treatment $j$ in project $i$ in year $t$; $A$ is the total budget in planning period; $T$ is the length of planning period, normally 5 or 10 years; $N$ is the amount of total road units; $m$ is the total number of treatments for each project.

The model above is a large integer programming problem in which the set of feasible solutions is very huge. Therefore, it is necessary to simplify the model in order to calculate 
conveniently as well as meeting practical needs. Equation (1) is transformed to the following form:

$$
\begin{aligned}
\sum_{t=1}^{T} \sum_{i=1}^{N} \sum_{j=1}^{m} X_{i j t} * B_{i j t}= & \sum_{i=1}^{N} \sum_{j=1}^{m} X_{i j 1} * B_{i j 1} \\
& +\cdots+\sum_{i=1}^{N} \sum_{j=1}^{m} X_{i j k} * B_{i j k} \\
& +\cdots+\sum_{i=1}^{N} \sum_{j=1}^{m} X_{i j T} * B_{i j T}
\end{aligned}
$$

If the expression $f_{t}\left(Y_{t}\right)=\sum_{i=1}^{N} \sum_{j=1}^{m} X_{i j t} * B_{i j t}$ (Y $Y_{t}$ is the budget of year $t$ ) is considered as the maintenance benefit of year $t$, then the total maintenance benefit in planning years should be equal to the summation of maintenance benefit of each year. Therefore,

$$
\begin{aligned}
\sum_{t=1}^{T} \sum_{i=1}^{N} \sum_{j=1}^{m} X_{i j t} * B_{i j t} & =f_{1}\left(Y_{1}\right)+\cdots+f_{t}\left(Y_{t}\right)+\cdots+f_{T}\left(Y_{T}\right) \\
& =\sum_{t=1}^{T} f_{t}\left(Y_{t}\right)
\end{aligned}
$$

where $Y_{t}$ is budget of year $t$ and $f_{t}\left(Y_{t}\right)$ is maintenance benefit of year $t$.

It is shown in (1) and (7) that solution of project optimization can be approached with the following steps. The first step is budget optimizing to get the budget allocation in each year in the planning period. The second step is project portfolio (including optimization of project scheme and schedule) to get the optimal benefit maintenance strategy in each year based on the budget allocation of first step. After several iterations of optimization, selection, and comparison through the repetition of above two steps, the optimal maintenance strategy under the optimal budget allocation can be achieved finally. Actually, this method reflects well the actual iterative decision-making process of the government agencies, which is "budget allocation, project arrangement, budget adjustment, and project adjustment." Through this iterative method, project optimization is divided into two relatively simple processes, namely, budget optimization and project distribution.

\section{Two-Stage Optimization Approach}

According to the above analysis, project optimization can be divided into two stages. The first one is about how to allocate budgets. The second one determines maintenance projects in each year based on the budget allocation in the first stage. The first stage is defined as budget allocation model and the second as project distribution model, which build up the twostage optimization approach.

3.1. Budget Allocation Model. Budget allocation model is, under certain amount of fund, to find a reasonable budget allocation for each year in planning period in order to maximize the benefit of budget. The model focuses on the reasonable way of budget allocation.

In the process of allocating budgets, pavement management agencies need to consider not only the performance of road network but also the budget limits (maximal and minimal budgets for each year are expressed with $S_{t}$ and $V_{t}$, resp.). Therefore, the budget allocation model can be designed as follows:

$$
\text { Objective } \quad \begin{aligned}
\max \sum_{t=1}^{T} f_{t}\left(Y_{t}\right) & =f_{1}\left(Y_{1}\right)+f_{2}\left(Y_{2}\right) \\
& +\cdots+f_{t}\left(Y_{t}\right)+\cdots+f_{T}\left(Y_{T}\right)
\end{aligned}
$$

$$
\begin{gathered}
\text { Subject to } \quad \sum_{t=1}^{T} Y_{t} \leq A \\
Y_{t} \leq S_{t} \quad(t=1,2, \ldots, T) \\
Y_{t} \geq V_{t} \quad(t=1,2, \ldots, T) .
\end{gathered}
$$

In fact, there are a large number of maintenance projects in the road network for the planning period, and each project has several treatments. Different treatments bring different maintenance benefits. Therefore, it is necessary to pose some limitations to budget allocation considering that pavement management agencies may utilize fuzzy decisions unconsciously in the process of decision-making which makes their decisions rather reasonable. Firstly, budget change is discontinuous when management agencies are allocating or adjusting budgets; therefore the budget change is set as integer times of the smallest unit. Secondly, maximal maintenance benefit in the planning period under certain budget allocation schedule equals the summation of maximal benefits in each year:

$$
\begin{aligned}
\sum_{t=1}^{T} f_{t}\left(Y_{t}\right)= & \max \left(f_{1}\left(Y_{1}\right)\right)+\cdots+\max \left(f_{t}\left(Y_{t}\right)\right) \\
& +\cdots+\max \left(f_{T}\left(Y_{T}\right)\right)=\sum_{t=1}^{T} \max \left(f_{t}\left(Y_{t}\right)\right) .
\end{aligned}
$$

3.2. Project Distribution. Project distribution model is about how to arrange maintenance projects under given budget allocation schedule $\left(Y_{1}, Y_{2}, \ldots, Y_{T}\right)$ in each year in order to obtain the maximal maintenance benefit. It can be designed as follows:

$$
\text { Objective } \sum_{t=1}^{T}\left(\max \sum_{i=1}^{n} \sum_{j=1}^{m}\left(X_{i j t} B_{i j t}\right)\right)
$$

Subject to $\sum_{i=1}^{n} \sum_{j=1}^{m}\left(X_{i j t} C_{i j t}\right) \leqq Y_{t}, \quad(t=1,2, \ldots, T)$

$$
\sum_{j=1}^{m} X_{i j t} \leq 1 \quad(i=1,2, \ldots, n ; t=1,2, \ldots, T), \quad X_{i j t}=0 \text { or } 1
$$




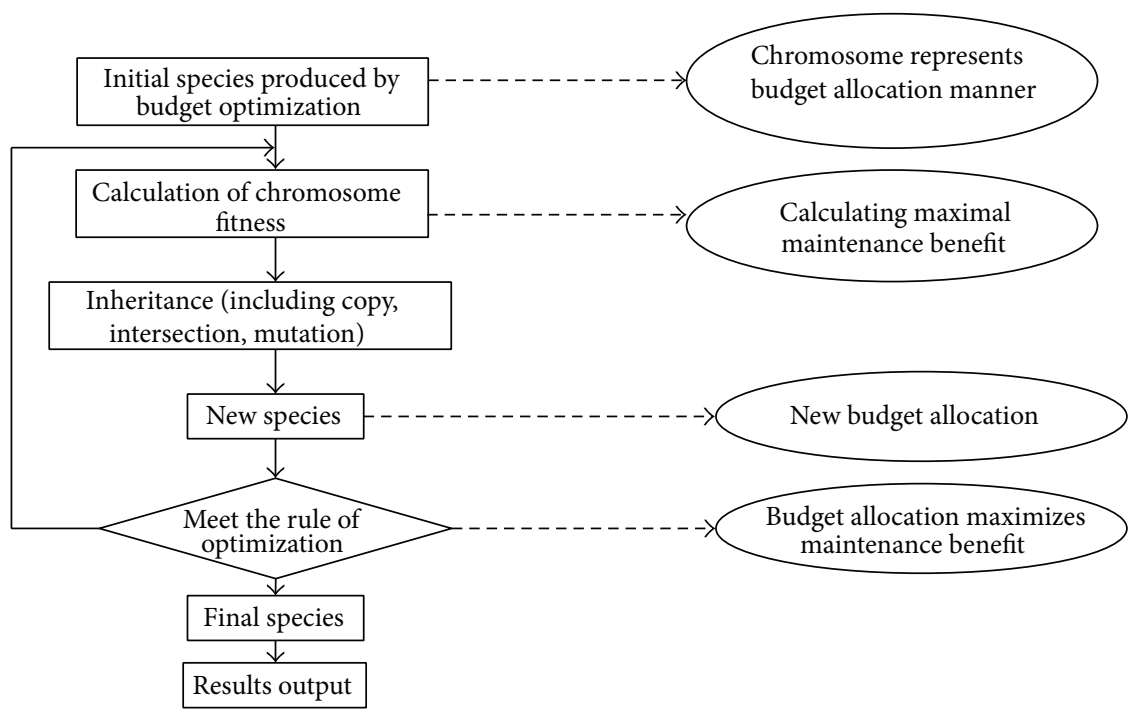

FIGURE 1: Calculation process of budget allocation with GA.

where $n$ is the total amount of projects in road network; $m$ is the total amount of treatments for each project; Boolean variable $X_{i j t}=1$ (or 0 ) means treatment $j$ is applied (or not) to project $i$ in year $t$.

3.3. Relation of Budget Allocation Model and Project Distribution Model. The results of the budget allocation model and the project distribution model are interactional. At first, annual budget will be provided through the budget allocation model. Then, the maximal maintenance benefit and the project schedule will be constructed through the project distribution model according to the result of the first model and then a feedback will be offered to the first model to judge whether the solution is the best or not. If not, the budget allocation model will optimize again and produce a new array of budgets in each year, then the corresponding total maintenance benefit and maintenance schedule will be obtained through the project distribution model. Through iterations of the two models, the optimal strategy will be obtained in the planning years.

\section{Solving the Two-Stage Model}

The key to applying the mathematic optimization method into practice is to find a reasonable solving method which ensures certain accuracy and meets practical requirements. In the objective function of (8), it is difficult to be expressed for $f_{i}\left(Y_{i}\right)$ by explicit functions, which causes difficulty in effectively solving it with normal algorithm. Given that genetic algorithm (GA) is able to search the global optimal solution in a complicated space while its objective functions are not necessary to be explicit functions, GA is chosen to solve the budget allocation model (8).

In the budget allocation model, decision (maintenance strategy) of each stage (planning year) is the function of pavement network condition given by the decision of last stage. That is, each stage will influence the next stage through the network condition resulting from the different treatment strategy. Therefore, under a given budget allocation $\left(Y_{1}, Y_{2}, \ldots, Y_{T}\right)$, the formulation of pavement network maintenance strategy in planning years is a multistage problem in which all stages have mutual connections, namely, a classic dynamic programming problem. Therefore, the method of dynamic programming is employed to solve the projects distribution model (13).

4.1. GA for Budget Allocation Model. Before the calculation with GA, some parameters including length of chromosome, species group scale, intersection rate, and mutation rate have to be set in advance according to the scale of pavement network, length of planning period, and budget. Then, the budget allocation model can be solved in the following process, as shown in Figure 1.

(1) Initial species: each chromosome in the species represents a budget allocation mode.

(2) Fitness function: the fitness function of chromosome is derived from the maximal maintenance benefit under a budget allocation mode. The function is computed using the project allocation model.

(3) Genetic manipulation of chromosome: through the genetic manipulation of chromosome, the budget allocation with superior maintenance benefit can be inherited and those inferior ones will be eliminated.

(4) Termination of iteration: certain iteration times can be set as the termination condition of GA.

In the above calculation process, the fitness function of chromosomes, which are not subject to the budget constraints, can be limited by penalty function or be given a very small fitness value. The chromosome with the biggest fitness value gets to be obtained by GA and the corresponding budget allocation manner is the final solution of the budget allocation model. 


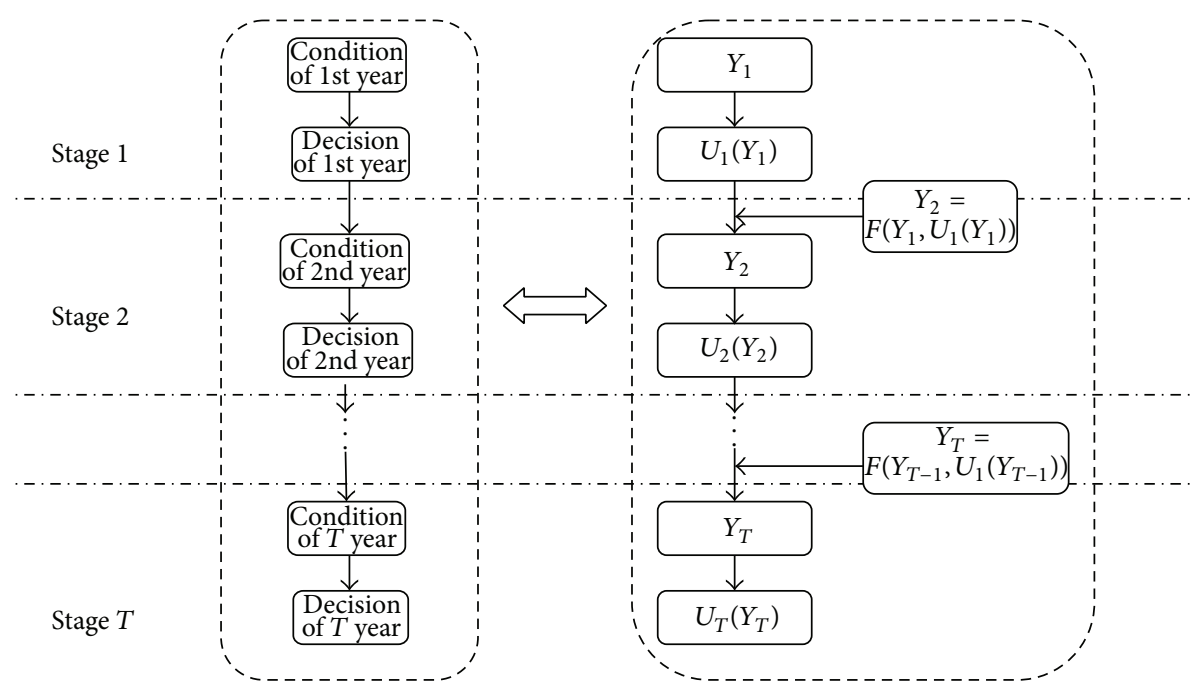

FIGURE 2: DP process of project distribution model.

4.2. DP for Project Distribution Model. Project distribution model is mainly used to arrange project implementation in each year under a given optimization result of budget allocation. The output results should include a list of maintenance projects in each planning year. Meanwhile, through the project distribution model, the fitness value can be achieved for the above-mentioned chromosome which can serve as the basis of calculation for further optimization.

As discussed above, the determination of maintenance strategy of pavement network in each stage is a multistage decision-making problem in which each stage is interactional. The process has the following characters: at the beginning of each stage, optimal decision of each stage is only related to road network condition, but not related to the decision of the previous stage in which the road network condition is known. The combination of optimal decision in each stage is the best strategy for the planning period. On the other hand, the process of decision-making is a multistage chain in which each stage does not influence the following stages. Therefore, the dynamic programming is a powerful tool to solve this kind of problem.

4.2.1. Calculation Process of DP. According to the characteristics of DP and project distribution model, the process of DP in project distribution can be described as shown in Figure 2.

In Figure 2, the whole planning period of $T$ years can be divided into $T$ stages. Vector $Y_{t}$ (pavement network condition in year $t$, budget of year $t$ ) represents initial condition of each stage. The decision can be made according to $U_{t}\left(Y_{t}\right)=U_{t}$ (pavement network condition in year $t$, budget of year $t$ ). Finally the maximal maintenance benefit, benefit in this stage, can be calculated based on the $U_{t}\left(Y_{t}\right)$ and the condition transition function $Y_{t}+1=F\left(Y_{t}, U_{t}\left(Y_{t}\right)\right)$.

4.2.2. The Calculation of Maximal Maintenance Benefit (Determination of $U_{t}\left(Y_{t}\right)$ ). Calculation model of maximal maintenance benefit $U_{t}\left(Y_{t}\right)$ in each year can be devised as follows:

$$
\begin{aligned}
& \max \sum_{i=1}^{n} \sum_{j=1}^{m}\left(X_{i j} B_{i j}\right) \\
& \text { s.t } \quad \sum_{i=1}^{n} \sum_{j=1}^{m}\left(X_{i j} C_{i j}\right) \leq y \\
& \sum_{j=1}^{m} X_{i j} \leq 1, \quad X_{i j}=0 \text { or } 1,
\end{aligned}
$$

where $n$ is the number of projects; $m$ is the number of treatments for each project; $y$ is the total maintenance budget; $X_{i j}=1$ (or 0 ) means treatment $j$ is selected (or not) in project $i$.

The following is a recursion equation built up by the DP method, in which there are 3 treatments for each project. The cost of each treatment is defined as integer and described from small to large as $w_{i 1}, w_{i 2}$, and $w_{i 3}$. At the same time, the corresponding benefit is $v_{i 1}, v_{i 2}$, and $v_{i 3}$, respectively:

$$
\begin{aligned}
& f(i, m) \\
& = \begin{cases}f(i+1, m) & 0<m<w_{i 1} \\
\max (f(i+1, m), & \\
\left.\quad f\left(i+1, m-w_{i 1}\right)+v_{i 1}\right) & w_{i 1}<m<w_{i 2} \\
\max \left(f(i+1, m), f\left(i+1, m-w_{i 1}\right)\right. & \\
\left.\quad+v_{i 1}, f\left(i+1, m-w_{i 2}\right)+v_{i 2}\right) & w_{i 2}<m<w_{i 3} \\
\max \left(f(i+1, m), f\left(i+1, m-w_{i 1}\right)\right. & \\
\quad+v_{i 1}, f\left(i+1, m-w_{i 2}\right)+v_{i 2}, & \\
\left.\quad f\left(i+1, m-w_{i 3}\right)+v_{i 3}\right) & X_{i}>m>w_{i 3} .\end{cases}
\end{aligned}
$$


TABLE 1: Results of new method.

\begin{tabular}{|c|c|c|c|c|c|c|}
\hline Year & $\begin{array}{c}\text { No. of segments to } \\
\text { be treated }\end{array}$ & $\begin{array}{l}\text { Length of road to } \\
\text { be treated }(\mathrm{m})\end{array}$ & $\begin{array}{l}\text { Area of pavement } \\
\text { to be treated }\left(\mathrm{m}^{2}\right)\end{array}$ & $\begin{array}{l}\text { Total maintenance } \\
\text { cost }(¥ 10,000)\end{array}$ & $\begin{array}{c}\text { Average PCI of } \\
\text { pavement network }\end{array}$ & $\begin{array}{c}\text { Average PII of } \\
\text { pavement } \\
\text { network }\end{array}$ \\
\hline 2005 & 60 & 17859 & 187210 & 1320 & 89.6 & 483649.2 \\
\hline 2006 & 56 & 17234 & 223318 & 1470 & 88.3 & 361548 \\
\hline 2007 & 63 & 17298 & 221853 & 1540 & 87.1 & 571428.7 \\
\hline 2008 & 81 & 23026 & 303050 & 1450 & 86.8 (minimal) & 888703.5 \\
\hline 2009 & 89 & 23103 & 307059 & 1700 & 87 & 782662.4 \\
\hline 2010 & 112 & 28812 & 334866 & 1670 & 88.3 & 780185.2 \\
\hline 2011 & 85 & 22393 & 310335 & 1670 & 88.8 & 755266.7 \\
\hline 2012 & 80 & 22567 & 328590 & 1660 & 89.3 & 675452.1 \\
\hline 2013 & 98 & 22582 & 272024 & 1700 & 90.6 & 520031.3 \\
\hline 2014 & 75 & 22688 & 319542 & 1580 & 91.1 (minimal) & 504012.8 \\
\hline Total & 799 & 217562 & 2807847 & 15760 & 88.69 & 6322940 \\
\hline
\end{tabular}

Then constraints can be formulated as follows:

$$
f(n, m)= \begin{cases}0 & m<w_{n 1} \\ v_{n 1} & w_{n 2}<m<w_{n 1} \\ \max \left(v_{n 1}, v_{n 2}\right) & w_{n 2}<m<w_{n 3} \\ \max \left(v_{n 1}, v_{n 2}, v_{n 3}\right) & m>w_{n 3} .\end{cases}
$$

The function of $f(i, m)$ can be solved through the backward deduction method and the optimal solution for each stage can be achieved through the backtracking method.

\section{Model Verification through Case Study}

The model and algorithm are tested and verified through a case study with the data collected from asphalt pavements of 12 districts in Shanghai in 2004. The planning period lasts 10 years, the total number of sections surveyed is 867 , the total road length is 238,332 meters, and the total area is 3,093,293 square meters.

(1) Parameters of funds are provided as follows:

(a) total budget: 160 million RMB,

(b) minimum investment for each year: 13 million $\mathrm{RMB}$,

(c) maximum investment for each year: 17 million $\mathrm{RMB}$,

(d) the step change of investment for each year: 100 thousand RMB.

(2) Parameters of GA are provided as follows:
(a) reproduction rate: 0.7 ,
(b) mutation rate: 0.05 ,
(c) crossover rate: 0.3 .

The calculation software is programmed with Microsoft Visual Basic 6.0. The model proposed and developed in this paper (hereafter referred to as "new method") is compared

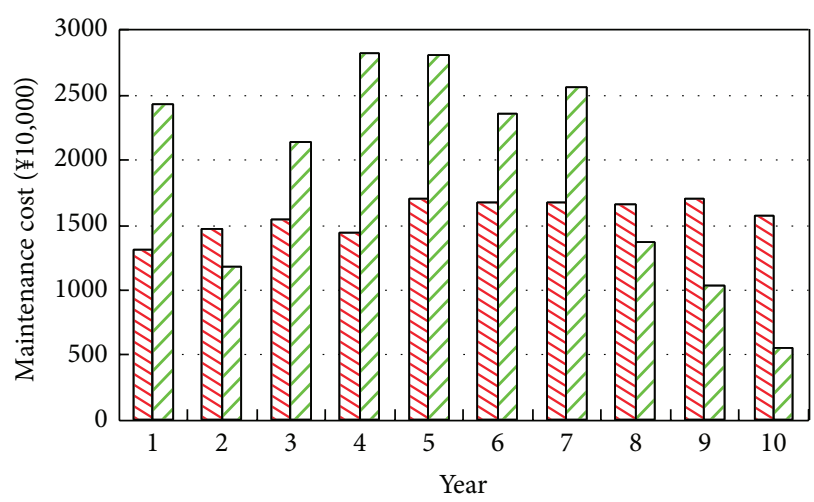

$\square$ New method
$\square$ Conventional method

FIGURE 3: Maintenance cost comparison of road network.

with the current pavement maintenance method (hereafter referred to as "conventional method"), in which maintenance would be conducted once the PCI is lower than 75, currently adopted by pavement management agencies in Shanghai. The calculation results are listed in Tables 1 and 2 .

In the tables, the maintenance benefit of the pavement network is indicated with PII (Pavement Improvement Index). PII mainly considers restoration of pavement indicators, interval time between two maintenance services, and social impact. The comparison of the data in Tables 1 and 2 is shown in Figures 3 and 4.

Based on the case study results, the following observations can be drawn.

(1) The total maintenance benefit increases (the PII improves from 6246469 to 6322940 after optimization with the new method), while the average PCI of road network in the planning period decreases after adopting the new method. At the same time, the total cost in the planning period is significantly reduced (the total cost decreases from $¥ 19286$ to $¥ 15760$, a drop 
TABLE 2: Results of conventional method.

\begin{tabular}{|c|c|c|c|c|c|c|}
\hline Year & $\begin{array}{c}\text { No. of segments to } \\
\text { be treated }\end{array}$ & $\begin{array}{l}\text { Length of road to } \\
\text { be treated }(\mathrm{m})\end{array}$ & $\begin{array}{l}\text { Area of pavement } \\
\text { to be treated }\left(\mathrm{m}^{2}\right)\end{array}$ & $\begin{array}{l}\text { Total maintenance } \\
\text { cost }(¥ 10,000)\end{array}$ & $\begin{array}{c}\text { Average PCI of } \\
\text { pavement network }\end{array}$ & $\begin{array}{c}\text { Average PII of } \\
\text { pavement } \\
\text { network }\end{array}$ \\
\hline 2005 & 78 & 24152 & 269404 & 2440 & 90.27 & 572719 \\
\hline 2006 & 43 & 13433 & 173309 & 1188 & 88.58 (minimal) & 302004 \\
\hline 2007 & 73 & 20923 & 257218 & 2145 & 87.88 & 621756 \\
\hline 2008 & 133 & 37972 & 461683 & 2820 (maximal) & 89.26 & 1131875 \\
\hline 2009 & 121 & 33224 & 446845 & 2810 & 90.77 & 962347 \\
\hline 2010 & 118 & 29992 & 366621 & 2356 & 92.51 & 749037 \\
\hline 2011 & 115 & 31383 & 435860 & 2559 & 94.38 & 864322 \\
\hline 2012 & 79 & 19932 & 279639 & 1370 & 95.09 & 551289 \\
\hline 2013 & 63 & 15851 & 224198 & 1039 & 95.13 (maximal) & 340663 \\
\hline 2014 & 34 & 8620 & 130474 & 559 (minimal) & 94 & 150450 \\
\hline Total & 857 & 235482 & 3045251 & 19286 & 91.78 (average) & 6246469 \\
\hline
\end{tabular}

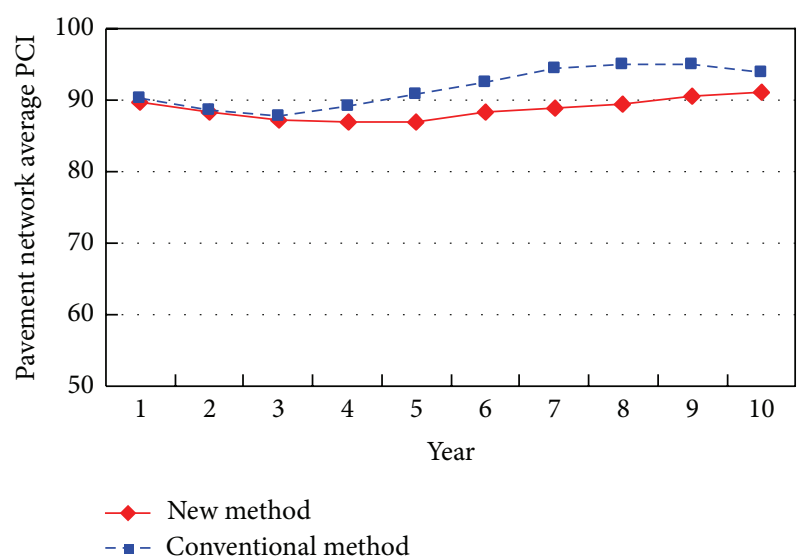

FIgURE 4: Average PCI comparison of road network.

of $18 \%)$. That is, pavement management agencies will achieve better maintenance benefit through spending fewer resources with the new method.

(2) As shown in Figure 3, through the conventional method, budget demand in each planning year is significantly different (i.e., the maximal budget demand is $¥ 28,200,000$ in the fourth year, and the minimal demand is $¥ 5,590,000$ in the tenth year. The variance of the investment in each year is up to 2447). That seriously violates the rule of a stable financial plan of local finance department. Through the new method, the budget of each planning year is well-controlled. The difference of each year's budget effectively decreases (i.e. the maximal budget demand is $¥ 17,000,000$ in the fifth and ninth year, and the minimal demand is $¥ 13,200,000$ in the first year. The variance of the investment in each year is lowered down to 387). It well reflects the rule of a stable financial plan of finance department.

(3) Figures 4 and 5 indicate that the PCI and the PII of road network in each year, similar to the maintenance

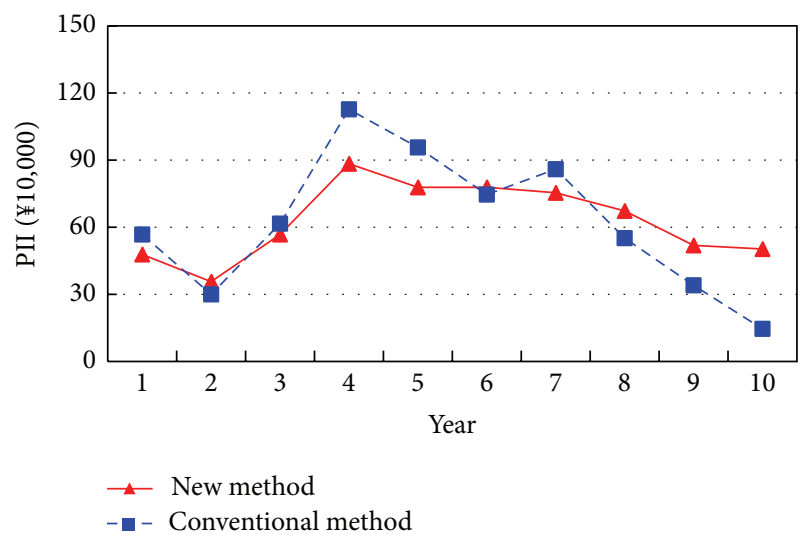

Figure 5: PII comparison.

budget, change remarkably when adopting the conventional method. On the contrary, the new method can significantly mitigate the variation of PCI and PII. The variance of PCI decreases from 8.3 to 4.5 and the variance of PII decreases from 928403 to 505346.

In general, pavement management agencies will get more maintenance benefit with fewer funds through the new model. Meanwhile, the amount of investment and the variability of pavement network PCI in each planning year can be effectively controlled to meet the rule of a stable project plan for pavement management agencies. Consequently, the new model and the solving method proposed in this paper are effective and practical for the infrastructure management.

\section{Conclusion}

Choosing a proper model and algorithm is very critical for methods of mathematic optimization. To solve the problems of poor calculation speed and practical application limitation of the conventional mathematic method, a two-stage model consisting of the budget allocation model and the project distribution model is developed in this paper. In addition, 
the model is solved through dynamic programming and genetic algorithm. Furthermore, it is verified to be effective by practical data in a case study. The findings indicate that the new optimization method can provide a satisfactory and reasonable maintenance schedule for transportation infrastructure maintenance agencies whose routine management will benefit from the newly proposed model.

\section{Conflict of Interests}

The authors declare that there is no conflict of interests regarding the publication of this paper.

\section{References}

[1] T. Hegazy, "Optimization of resource allocation and leveling using genetic algorithms," Journal of Construction Engineering and Management, vol. 125, no. 3, pp. 167-175, 1999.

[2] N. Bandara and M. Gunaratne, "Current and future pavement maintenance prioritization based on rapid visual condition evaluation," Journal of Transportation Engineering, vol. 127, no. 2, pp. 116-123, 2001.

[3] T. F. Fwa, K. C. Sinha, and J. D. N. Riverson, "Highway routine maintenance programming at network level," Journal of Transportation Engineering, vol. 114, no. 5, pp. 539-554, 1988.

[4] R. Hass, W. R. Hudson, and J. Zaniewski, Modern Pavement Management, Krieger, Malabar, Fla, USA, 1994.

[5] J. J. Hajek and W. A. Phang, "Prioritization and optimization pavement of preservation treatments," Transportation Research Record 1216, National Research Council, Washington, DC, USA, 1989.

[6] P. B. Still, "A Pavement management system for UK roads," Highways and Transportation, vol. 37, no. 2, pp. 6-9, 1990.

[7] R. Haas, "A method for integrated priority programming and budget level analysis for pavement maintenance and rehabilitation," in Proceedings of the 5th International Conference on the Structure Design of Asphalt Pavements, vol. 1, pp. 626-635, Delft, The Netherlands, 1982.

[8] R. Dekker, R. E. Wildeman, and F. A. van der Duyn Schouten, "A review of multi-component maintenance models with economic dependence," Mathematical Methods of Operations Research, vol. 45, no. 3, pp. 411-435, 1997.

[9] P. Ullidtz, "A danish pavement management system," in Proceedings of the NAPMC, vol. 3, pp. 6.84-6.95, Toronto, Canada, 1985.

[10] D. Mrawira, W. J. Welch, M. Schonlau, and R. Haas, "Sensitivity analysis of computer models: World bank HDM-III model," Journal of Transportation Engineering, vol. 125, no. 5, pp. 421428, 1999.

[11] S. Chi, J. Hwang, M. Arellano, Z. Zhang, and M. Murphy, "Development of network-level project screening methods supporting the 4-year pavement management plan in Texas," Journal of Management in Engineering, vol. 29, no. 4, pp. 482494, 2013.

[12] R. Kher and W. D. Cook, "PARS: the MTC mode for programming and financial planning in pavement rehabilitation," in Proceedingsof the National Arts Marketing Project Conference (NAMPC '85), vol. 3, pp. 6.23-6.40, Toronto, Canada, 1985.

[13] B. Colucci-Rios and K. C. Sinha, "An optimal pavement management system at the network level," in Proceedings of the 1st North American Pavement Management Conference (NAPMC '85), vol. 3, pp. 6.68-6.83, Toronto, Canada, 1985.
[14] R. F. Carmicheal, "Implementing pavement management system at the Indiana Department of Highways," in Proceedings of the 6th International Conference on Structure Design of Asphalt Pavements, vol. 1, pp. 834-857, Ann Arbor, Mich, USA, 1987.

[15] K. Golabi, R. B. Kulkarni, and G. B. Way, "A statewide pavement management system,” Interfaces, vol. 12, no. 6, pp. 5-21, 1982.

[16] K. J. Feighan, M. Y. Shahin, and K. C. Sinha, "A dynamic programming approach to optimization for pavement management systems," in Proceedings of Second North American Conference on Managing Pavements (SNACMP '87), vol. 2, pp. 195-206, Toronto, Canada, 1987.

[17] B. Liu and Z. Yao, "Optimization method in network pavement management system," China Journal of Highway and Transport, vol. 7, no. 3, pp. 1-9, 1994.

[18] P.Zou, "On optimization method of pavement maintenance and rehabilitation programming," China Journal of Highway and Transport, vol. 8, no. 2, pp. 1-8, 1995.

[19] C. Nunoo, Optimization of Pavement Maintenance and Rehabilitation programming Using Shuffled Complex Evolution Algorithm, Florida International Univesrity, Miami, Fla, USA, 2001.

[20] W. T. Chan, T. F. Fwa, and J. Y. Tan, "Optimal fund-allocation analysis for multidistrict highway agencies," Journal of Infrastructure Systems, vol. 9, no. 4, pp. 167-175, 2003.

[21] T. F. Fwa, W. T. Chan, and K. Z. Hoque, "Multiobjective optimization for pavement maintenance programming," Journal of Transportation Engineering, vol. 126, no. 5, pp. 367-374, 2000.

[22] A. Ferreira, A. Antunes, and L. Picado-Santos, "Probabilistic segment-linked pavement management optimization model," ASCE Journal of Transportation Engineering, vol. 128, no. 6, pp. $568-577,2002$. 


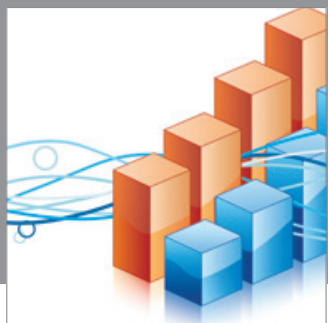

Advances in

Operations Research

mansans

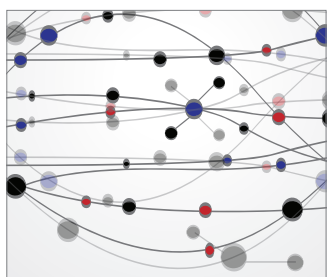

The Scientific World Journal
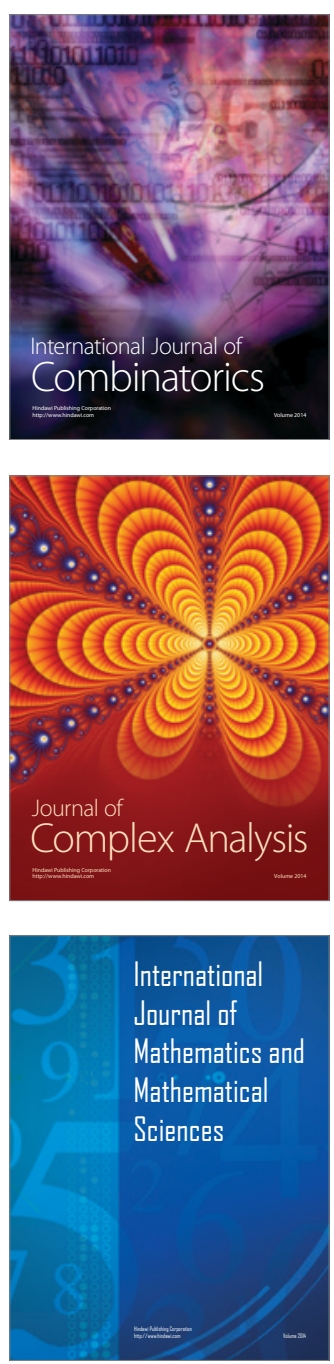
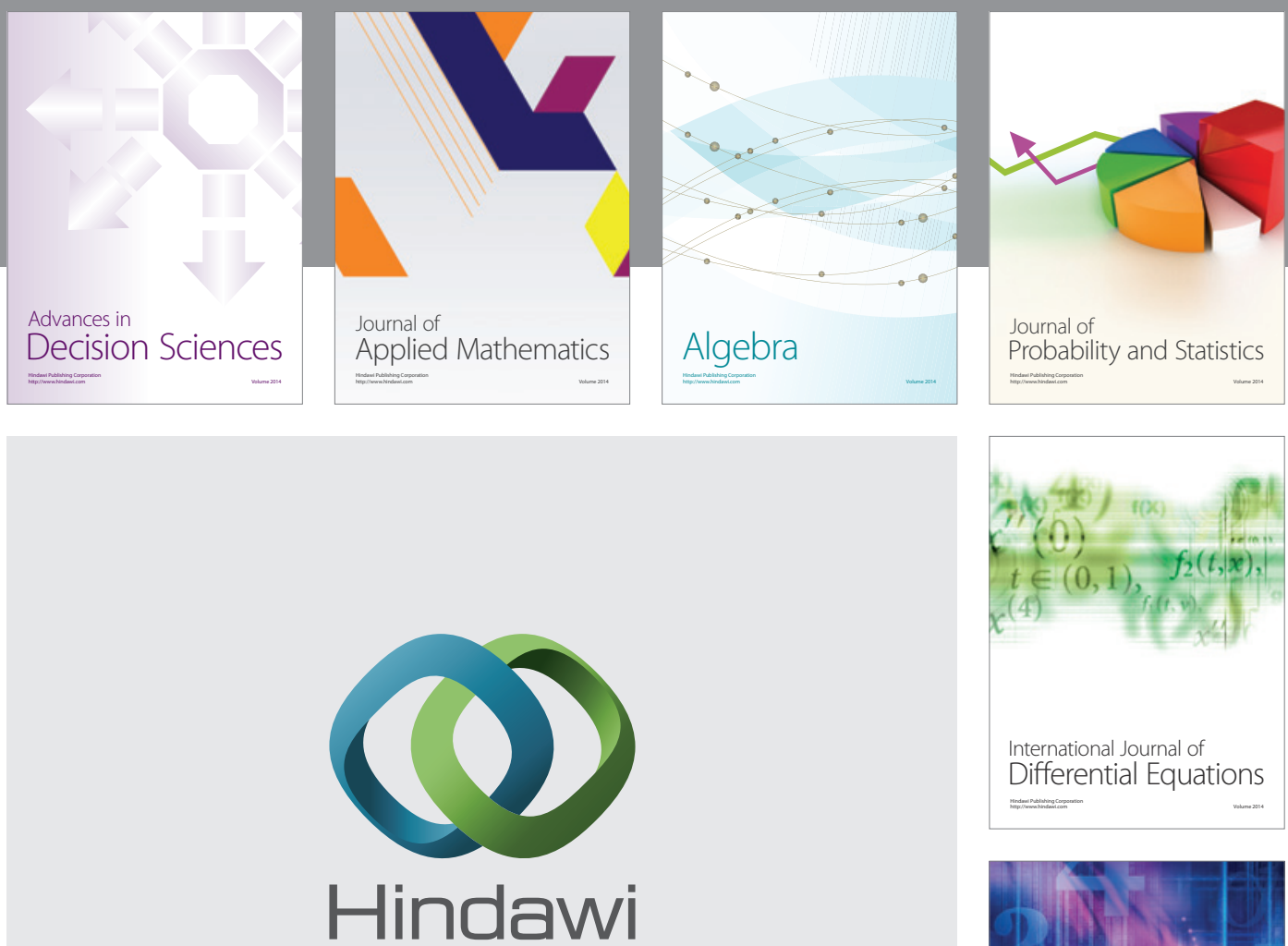

Submit your manuscripts at http://www.hindawi.com
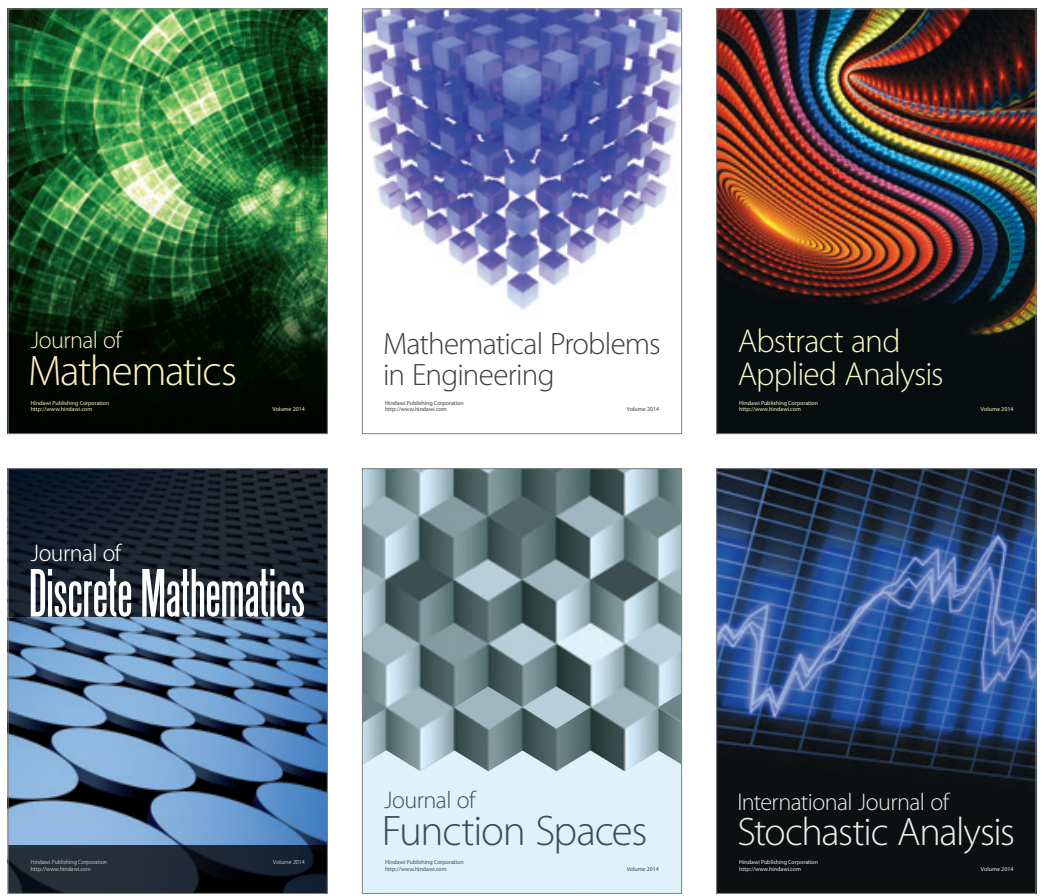

Journal of

Function Spaces

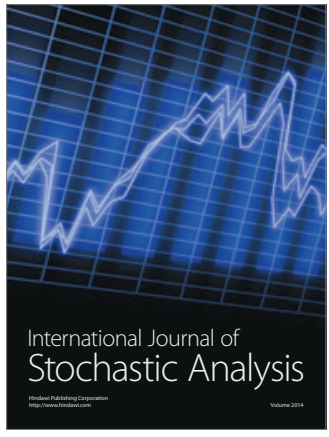

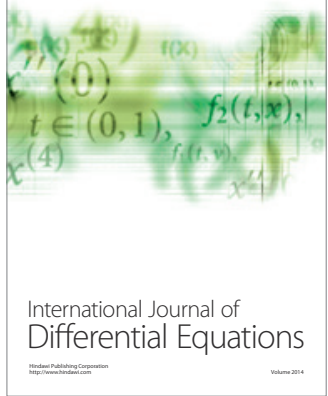
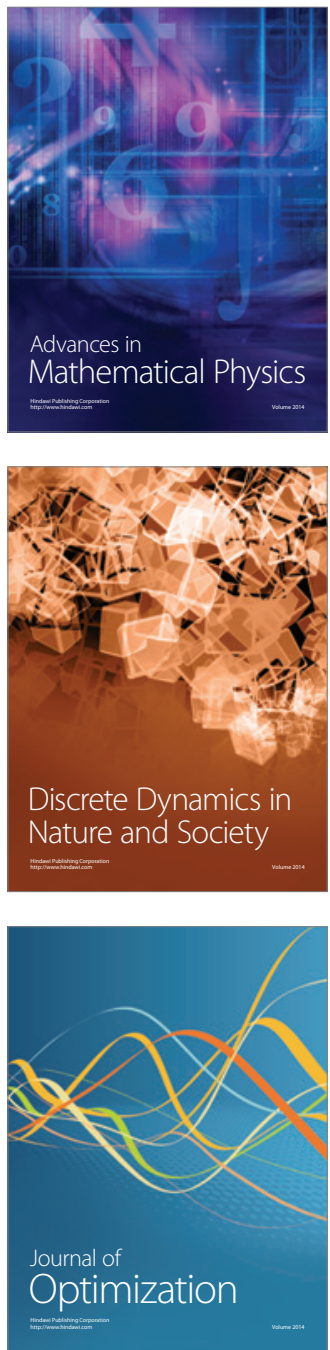